\title{
Análise florística, estrutural e fitogeográfica da vegetação em região de transição entre as Florestas Ombrófilas Mista e Densa Montana, Piraquara, Paraná, Brasil
}

\author{
Marcelo Reginato ${ }^{1,2}$ e Renato Goldenberg ${ }^{1}$
}

Recebido: 21.12.2006; aceito: 09.07.2007

ABSTRACT - (Floristic, structure and phytogeography of vegetation in a transition region between Araucaria and Montane Atlantic Forests, Piraquara, Paraná, Brazil). In this work we characterize the composition and the structure of the arboreal vegetation and analyze the geographic distribution of the species sampled in a transitional region between the Araucaria Forest and Montane Atlantic Rainforest in Piraquara, Paraná. We sampled 617 individuals, distributed in 31 families and 85 species. The most diverse families were Myrtaceae (22 species), Lauraceae (11), Rubiaceae (6) and Aquifoliaceae (4). The most important species in the structural analyses were Alsophila setosa, Ocotea catharinensis, Cyathea phalerata, Cryptocarya aschersoniana and Cordiera concolor. It was possible to evidence that the Montane Atlantic Rainforest in the state of Paraná presents differentiated floristic composition, and the existence of a transitional gradient between Araucaria and Montane Atlantic in the Paraná's Atlantic range. Both composition and structure data indicate that the analyzed community is in advanced succession state and deserves rigorous conservation.

Key words: Araucaria Forest, Montane Atlantic Forest, Phytogeography, Phytosociology

RESUMO - (Análise florística, estrutural e fitogeográfica da vegetação em região de transição entre as Florestas Ombrófilas Mista e Densa Montana, Piraquara, Paraná, Brasil). Os objetivos deste trabalho foram caracterizar a composição e a estrutura da vegetação arbórea e analisar a distribuição geográfica das espécies amostradas em uma região de transição entre as Florestas Ombrófilas Mista e Densa Montana em Piraquara, Paraná. Foram amostrados 617 indivíduos, distribuídos em 31 famílias e 85 espécies. As famílias mais diversas foram Myrtaceae (22 espécies), Lauraceae (11), Rubiaceae (6) e Aquifoliaceae (4). Estruturalmente, as espécies mais importantes foram Alsophila setosa, Ocotea catharinensis, Cyathea phalerata, Cryptocarya aschersoniana e Cordiera concolor. Foi possível constatar que a Floresta Ombrófila Densa Montana no estado do Paraná apresenta composição florística diferenciada e ainda, a existência de um gradiente transicional entre as floras de Floresta Ombrófila Mista e Densa Submontana na Serra do Mar paranaense. Tanto os dados de composição como os estruturais indicam que a comunidade analisada se apresenta em estágio avançado de sucessão e merece rigorosa conservação.

Palavras-chave: Araucaria, Fitogeografia, Fitossociologia, Mata Atlântica

\section{Introdução}

A região dos Mananciais da Serra (Piraquara, $\mathrm{PR}$ ) representa uma das áreas com os últimos remanescentes de florestas bem conservadas na região de Curitiba, PR. Em virtude dos seus préstimos à manutenção da qualidade e água dos mananciais, a vegetação ali está sendo conservada há mais de um século. Apresenta ainda um caráter peculiar quanto a sua vegetação, pois é a região de encontro de duas grandes formações vegetacionais, a Floresta
Ombrófila Densa Montana com a Floresta Ombrófila Mista.

A Floresta Ombrófila Mista encontra sua principal área de distribuição nos três estados sulinos. É constituída principalmente por Araucaria angustifolia (Bertol.) Kuntze, cuja distribuição é coincidente com a desta formação, apresentando diferenças estruturais e fisionômicas ao longo de sua distribuição (Klein 1984, IBGE 1992, Leite 2002). No Paraná, a região das araucárias principia no Primeiro Planalto, imediatamente a oeste da Serra do Mar,

1. Universidade Federal do Paraná, Departamento de Botânica, Setor de Ciências Biológicas, Caixa Postal 19031, 81531-970 Curitiba, PR, Brasil

2. Autor para correspondência: reginatobio@yahoo.com.br 
estendendo-se também pelo Segundo e pelo Terceiro Planaltos (Maack 1981).

A Floresta Ombrófila Densa no sul do país ocupa as planícies quaternárias do Pleistoceno bem como as encostas da Serra do Mar. Consoante às diferentes situações topográficas e às condições edáficas locais, pode-se caracterizar diversas formações de composição, estrutura e fisionomia bem distintos, estabelecidos ao longo do litoral e da encosta atlântica (Leite 2002, Roderjan et al. 2002, Klein 1984). Trabalhos abordando a vegetação de Floresta Ombrófila Densa Montana, no Estado do Paraná, estão restritos a algumas dissertações e teses acadêmicas. Em áreas de Floresta Ombrófila Densa Montana destaca-se o trabalho realizado por Schorn (1992), onde o autor estudou a vegetação em três diferentes tipos de solo na Reserva de Guaricana (Guaratuba, PR) e, mais recentemente, o realizado por Blum (2006) na Serra da Prata (Morretes, PR), onde o autor caracterizou a composição e a estrutura da vegetação ao longo de um gradiente de altitude, na vertente atlântica desta serra. Em áreas de transição entre a Floresta Ombrófila Densa Montana e a Floresta Ombrófila Mista destacam-se os estudos realizados por Lacerda (1999) e Roderjan (1994). O primeiro realizou uma comparação florística e estrutural entre duas áreas em diferente estágio sucessional no Morro do Canal (Piraquara, PR) enquanto o segundo autor caracterizou a vegetação ao longo de um gradiente altitudinal no Morro do Anhangava (Quatro Barras, PR).

Este trabalho faz parte de um projeto que visa compreender a composição da Floresta Ombrófila Densa Montana paranaense e como ocorre a transição entre as Florestas Ombrófilas Mista e Densa no sul do Brasil. Para tanto, um levantamento florístico vem sendo realizado na região dos Mananciais da Serra desde junho de 2004. Foram objetivos deste trabalho: caracterizar a composição e a estrutura da vegetação arbórea na área de estudo através dos parâmetros fitossociológicos e analisar a distribuição geográfica das espécies amostradas.

\section{Material e métodos}

A localidade de Mananciais da Serra situa-se no município de Piraquara, PR, região metropolitana de Curitiba, extremo oeste do Primeiro Planalto Paranaense, ao sudoeste da Serra do Marumbi, coordenadas centrais aproximadas: $48^{\circ} 59^{\prime} \mathrm{W}$ e $25^{\circ} 29^{\prime} \mathrm{S}$. Esta área é gerenciada pela Companhia de
Saneamento do Paraná (SANEPAR) e está inserida dentro da Área de Especial Interesse Turístico do Marumbi (A.E.I.T.). A A.E.I.T. do Marumbi é uma unidade de conservação relativamente grande, com uma área de 66.732,99 ha e abrange partes dos municípios de Antonina, Morretes, São José dos Pinhais, Piraquara, Quatro Barras e Campina Grande do Sul (ITCF 1987).

A Serra do Mar, no Estado do Paraná constitui a zona limítrofe entre o Primeiro Planalto Paranaense e a Planície Costeira. Localizada nas vizinhanças do Oceano Atlântico, apresenta condições climáticas diferenciadas das demais regiões do estado, dadas suas peculiaridades geográficas (ITCF 1987). Segundo a classificação de Köppen, o clima enquadra-se no tipo $\mathrm{Cfb}$ (sub-tropical úmido), mesotérmico, com verões frescos, geadas freqüentes e sem estações secas. Apresenta temperatura média no mês mais frio de $12{ }^{\circ} \mathrm{C}$ e no mais quente de $20^{\circ} \mathrm{C}$. A precipitação média anual é de $1.384 \mathrm{~mm}$, sendo outubro, novembro e dezembro os meses mais chuvosos e junho, julho e agosto os mais secos (IAPAR 1994).

Para a realização do levantamento fitossociológico foi utilizada uma área de encosta, a cerca de 100 metros da represa do Braço Carvalho, entre 1.020 e $1.040 \mathrm{~m}$ de altitude que apresenta características fitofísionômicas de Floresta Ombrófila Densa Montana (IBGE 1992, Roderjan et al. 2002). Na área selecionada foi demarcada uma parcela de $120 \times 60 \mathrm{~m}$, que foi sub-dividida em parcelas de $10 \times 10 \mathrm{~m}$. A partir destas, elaborou-se um croqui e as sub-parcelas foram sorteadas e amostradas até a suficiência amostral ser atingida, o que foi verificado através da interpretação da curva de espécie/área (Mueller-Dombois \& Ellenberg 1974).

Foram levantados os indivíduos arbóreos, incluindo Pteridófitas arborescentes, que possuíam o perímetro à altura do peito (PAP), a 1,3 m acima do solo, igual ou superior a $10 \mathrm{~cm}(\mathrm{DAP}=3,2 \mathrm{~cm})$. A medição da altura de cada indivíduo foi estimada visualmente. A identificação das espécies quando possível foi realizada em campo. No caso de espécies desconhecidas, o material era coletado e herborizado segundo os procedimentos usuais (Fidalgo \& Bononi 1989).

A identificação das espécies foi realizada sempre ao menor nível taxonômico possível. Para tanto se utilizou bibliografia específica, consulta a especialistas e comparação com exsicatas do herbário do Museu Botânico Municipal (MBM) e do herbário do Departa- 
mento de Botânica da Universidade Federal do Paraná (UPCB). As espécies indeterminadas foram consideradas como espécies diferentes entre si e tratadas como morfoespécies. O material coletado fértil está sendo incorporado à coleção do UPCB. As espécies de Angiospermas e Pteridófitas foram agrupadas segundo o sistema de classificação proposto pelo Angiosperm Phylogeny Group (APG II 2003) e Smith et al. (2006), respectivamente, a nomenclatura está de acordo com o The International Plant Names Index (IPNI 2006).

Foram analisados os parâmetros usuais de fitossociologia propostos por Muller-Dombois \& Ellenberg (1974) e Magurran (1988), assim como o índice de agrupamento proposto por de Fracker \& Brischle (1994). Para as comparações de similaridade florística entre esta e algumas outras áreas realizou-se uma seleção de estudos em diferentes formações vegetacionais de interesse (figura 1 e tabela 1). Nos estudos realizados ao longo de um gradiente altitudinal (Roderjan 1994, Blum
2006) as composições de cada cota altimétrica foram analisadas individualmente. Dados de trabalhos onde foram amostradas mais de uma área em patamares altimétricos semelhantes foram tratados conjuntamente. As espécies listadas nestes levantamentos tiveram seus binômios atualizados, para evitar sinonímias que influíssem nos índices de similaridade e as espécies indeterminadas foram consideradas como espécies diferentes. A partir da matriz de dados binários (presença ou ausência da espécie em uma determinada área) foram calculados os índices similaridade de Sorensen, e utilizando a matriz de similaridade foi realizada uma análise de agrupamentos pelo método de médias aritméticas nãoponderadas (UPGMA) para a obtenção de um dendrograma. Particularmente, para comparação com o estudo realizado por França \& Stehmann (2005), utilizando a mesma matriz de dados, foi também calculado o índice de similaridade de Jaccard. Os dados foram tratados com o auxílio do programa Biodiversity Pro (Mcaleece 1997).

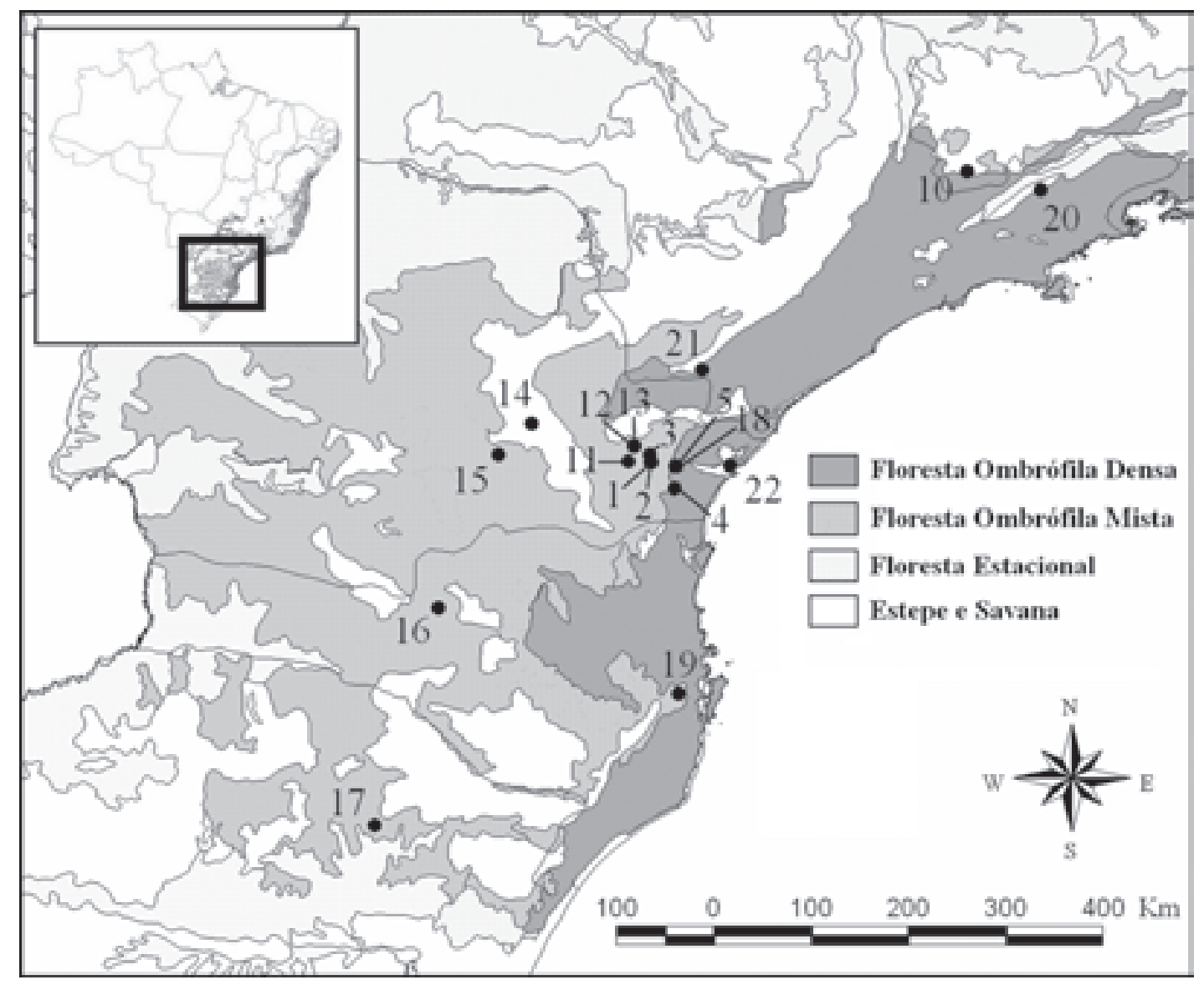

Figura 1. Mapa fitogeográfico de parte das regiões sul e sudeste do Brasil com a localização das 22 áreas utilizadas nas análises florísticas deste estudo. Os números representam as áreas que estão sumarizadas na tabela 1 . 
Tabela 1. Relação das 22 áreas utilizadas nas análises florísticas deste estudo. Estão listados o tipo vegetacional e o código de indentificação utilizado na tabela 3 e figuras 1 e 2, a localidade, o método de amostragem utilizado no estudo, o número de indivíduos amostrados, o DAP mínimo de inclusão, o número de espécies amostradas e a referência bibliográfica. FOM = Floresta Ombrófila Mista; FOD = Floresta Ombrófila Densa; $\mathrm{M}=$ Montana; $\mathrm{S}=$ Submontana; T = Terras Baixas; “"” = transição.

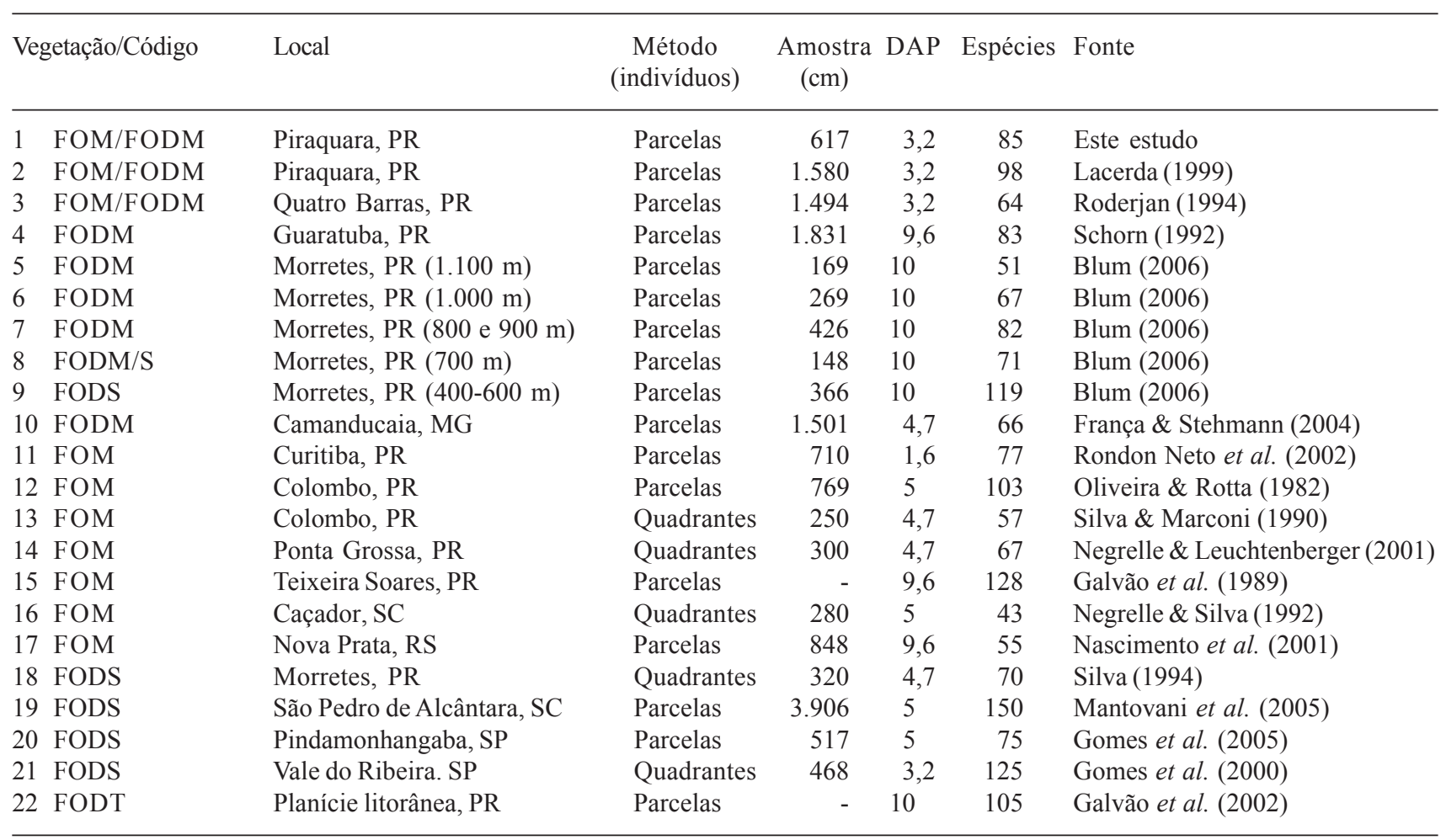

A caracterização da distribuição das espécies amostradas neste levantamento foi realizada com base nas suas respectivas coleções do herbário MBM, haja visto que este herbário conta com uma significativa amostragem florística deste estado e tratamentos taxonômicos não estão disponíveis para todos os táxons analisados. A Flora Ilustrada Catarinense, Flora Fanerogâmica do Estado de São Paulo e monografias, quando disponíveis, foram consultadas para verificar discrepâncias com relação aos dados encontrados no herbário. As espécies cujas coleções restringiram-se à planície litorânea e Serra do Mar foram consideradas preferenciais de Floresta Ombrófila Densa Submontana (FODS). As espécies que foram amostradas exclusivamente nos municípios do $1^{\circ}$ e $2^{\circ}$ Planalto Paranaense, em altitudes maiores que $800 \mathrm{~m}$ s.n.m., foram consideradas como preferenciais de Floresta Ombrófila Mista (FOM). As espécies que só foram amostradas na Serra do Mar paranaense e em municípios situados na transição entre esta e $01^{\circ}$ Planalto foram consideradas típicas da Floresta Ombrófila Densa Montana (FODM). Espécies que foram amostradas em mais de uma destas situações, ou ainda em áreas de Floresta Ombrófila Densa de Terras Baixas (FODT) e Floresta Estacional Semidecidual (FES), foram consideradas como de distribuição ampla. Tanto a listagem das distribuições como a matriz de presença ou ausência de espécies utilizada na análise de UPGMA estão disponíveis com o primeiro autor.

\section{Resultados e Discussão}

Composição - A suficiência amostral foi atingida após o levantamento de 28 parcelas de $100 \mathrm{~m}^{2}$, segundo a interpretação da curva espécie/área. A área amostral total constituiu 0,28 ha, onde foram amostrados 617 indivíduos, distribuídos em 31 famílias e 85 espécies (tabela 2). Destes, 74 foram determinadas ao nível específico, 6 ao nível genérico, 2 ao nível de família e 3 espécies não foram determinadas.

O índice de diversidade de Shannon-Weaver (H') obtido foi de 3,67 nats/ind ${ }^{-1}$ e a equitabilidade (J) 0,83 . A família Myrtaceae apresentou a maior riqueza específica (22 espécies), foi seguida por Lauraceae (11), Rubiaceae (6), Aquifoliaceae (4) e Salicaceae, 
Tabela 2. Lista das famílias e espécies amostradas em 0,28 ha de uma área situada na transição entre as Florestas Ombrófilas Densa Montana e Mista nos Mananciais da Serra, com as suas respectivas distribuições fitogeográficas e número de coleta ("MR" indica que foi coletado por M. Reginato e "nc" que o material não foi coletado fértil). FOM = Floresta Ombrófila Mista; FOD = Floresta Ombrófila Densa; $\mathrm{M}=$ Montana; $\mathrm{S}=$ Submontana.

\begin{tabular}{|c|c|c|}
\hline Família/Espécie & Distribuição & $\mathrm{N}^{\mathrm{o}}$ de coleta \\
\hline \multicolumn{3}{|l|}{ ANNONACEAE } \\
\hline Guatteria australis A. St.-Hil. & Ampla & MR 82 \\
\hline \multicolumn{3}{|l|}{ APOCYNACEAE } \\
\hline Aspidosperma pyricollum Müll. Arg. & Ampla & MR 102 \\
\hline \multicolumn{3}{|l|}{ AQUIFOLIACEAE } \\
\hline Ilex dumosa Reiss. & Preferencial de FOM & nc \\
\hline Ilex paraguariensis A. St.-Hil. & Preferencial de FOM & MR 477 \\
\hline Ilex taubertiana Loes. & Típica de FODM & MR 327 \\
\hline Ilex theezans Mart. & Ampla & MR 385 \\
\hline \multicolumn{3}{|l|}{ ARALIACEAE } \\
\hline Schefflera angustissima (Marchal) Frodin & Típica de FODM & MR 87 \\
\hline \multicolumn{3}{|l|}{ ARECACEAE } \\
\hline Geonoma schottiana Mart. & Indeterminada & MR 43 \\
\hline \multicolumn{3}{|l|}{ CELASTRACEAE } \\
\hline Maytenus robusta Reiss. & Ampla & MR 588 \\
\hline \multicolumn{3}{|l|}{ CUNONIACEAE } \\
\hline Lamanonia speciosa (Cambess.) L.B. Sm. & Preferencial de FOM & MR 140 \\
\hline Weinmannia paulliniifollia Pohl. ex Ser. & Ampla & MR 147 \\
\hline \multicolumn{3}{|l|}{ CYATHEACEAE } \\
\hline Alsophyla setosa Kaulf. & Ampla & $\mathrm{nc}$ \\
\hline Cyathea phalerata Mart. & Ampla & $\mathrm{nc}$ \\
\hline \multicolumn{3}{|l|}{ DICKSONIACEAE } \\
\hline Dicksonia sellowiana Hook. & Preferencial de FOM & nc \\
\hline \multicolumn{3}{|l|}{ ELAEOCARPACEAE } \\
\hline Sloanea lasiocoma K. Schum. & Preferencial de FOM & $\mathrm{nc}$ \\
\hline Sloanea sp. & Indeterminada & nc \\
\hline \multicolumn{3}{|l|}{ EUPHORBIACEAE } \\
\hline Alchornea triplinervia Müll. Arg. & Ampla & MR 104 \\
\hline \multicolumn{3}{|l|}{ LAURACEAE } \\
\hline Cinnamomum cf. triplinerve (Ruiz \& Pav.) Kosterm. & Indeterminada & MR 549 \\
\hline Cinnamomum pseudoglaziovii Lorea-Hernandez (inédita) & Indeterminada & $\mathrm{nc}$ \\
\hline Cryptocarya aschersoniana $\mathrm{Mez}$ & Ampla & $\mathrm{nc}$ \\
\hline Endlicheria paniculata (Spreng.) Macbride & Ampla & MR 504 \\
\hline Nectandra puberula Nees & Preferencial de FOM & MR 234 \\
\hline Ocotea catharinensis $\mathrm{Mez}$ & Ampla & $\mathrm{nc}$ \\
\hline Ocotea cf. corymbosa $\mathrm{Mez}$ & Ampla & MR 658 \\
\hline Ocotea elegans $\mathrm{Mez}$ & Ampla & MR 631 \\
\hline Ocotea glaziovii Mez & Ampla & MR 695 \\
\hline Ocotea odorifera (Vell.) Rohwer & Preferencial de FOM & MR 666 \\
\hline Ocotea pulchella Mart. & Ampla & MR 607 \\
\hline \multicolumn{3}{|l|}{ LEGUMINOSAE } \\
\hline Dalbergia frutescens (Vell.) Britton & Ampla & MR 640 \\
\hline Ormosia arborea Harms & Preferencial de FODS & nc \\
\hline \multicolumn{3}{|l|}{ MALPIGHIACEAE } \\
\hline Byrsonima ligustrifolia A. Juss. & Preferencial de FODS & MR 198 \\
\hline \multicolumn{3}{|l|}{ MELASTOMATACEAE } \\
\hline Leandra barbinervis (Triana) Cogn. & Típica de FODM & MR 19 \\
\hline Miconia petropolitana Cogn. & Preferencial de FOM & MR 23 \\
\hline Miconia sellowiana (DC.) Naudin & Ampla & MR 101 \\
\hline \multicolumn{3}{|l|}{ MELIACEAE } \\
\hline Cabralea canjerana (Vell.) Mart. & Ampla & MR 99 \\
\hline \multicolumn{3}{|l|}{ MONIMIACEAE } \\
\hline Mollinedia hatschbachii A.L. Peixoto & Típica de FODM & MR 24 \\
\hline Mollinedia uleana Perkins & Preferencial de FODS & $\begin{array}{l}\text { MR } 63 \\
\text { continu }\end{array}$ \\
\hline
\end{tabular}


Tabela 2 (continuação)

\begin{tabular}{|c|c|c|}
\hline Família/Espécie & Distribuição & $\mathrm{N}^{\mathrm{o}}$ de coleta \\
\hline \multicolumn{3}{|l|}{ MORACEAE } \\
\hline Sorocea bonplandii (Baill.) W.C. Burger, Lanj. \& Boer & Ampla & MR 547 \\
\hline \multicolumn{3}{|l|}{ MYRSINACEAE } \\
\hline Myrsine umbellate Mart. & Ampla & MR 209 \\
\hline \multicolumn{3}{|l|}{ MYRTACEAE } \\
\hline Calyptranthes cf. pileata D. Legrand & Típica de FODM & $\mathrm{nc}$ \\
\hline Eugenia $\mathrm{cf}$. burkartiana (D. Legrand) D. Legrand & Ampla & $\mathrm{nc}$ \\
\hline Eugenia handroana D. Legrand & Preferencial de FOM & $\mathrm{nc}$ \\
\hline Eugenia kleinii D. Legrand & Típica de FODM & MR 501 \\
\hline Eugenia pleurantha $\mathrm{O}$. Berg & Típica de FODM & nc \\
\hline Eugenia cf. schuechiana O. Berg & Preferencial de FODS & $\mathrm{nc}$ \\
\hline Eugenia sp. 1 & Indeterminada & nc \\
\hline Eugenia sp. 2 & Indeterminada & $\mathrm{nc}$ \\
\hline Eugenia sp. 3 & Indeterminada & $\mathrm{nc}$ \\
\hline Marlieria reitzii $\mathrm{D}$. Legrand & Típica de FODM & MR 201 \\
\hline cf. Myrceugenia ovalifolia (O. Berg) Landrum & Típica de FODM & nc \\
\hline Myrceugenia seriatoramosa (Kiaersk.) D. Legrand \& Kausel & Típica de FODM & MR 390 \\
\hline cf. Myrceugenia venosa D. Legrand & Típica de FODM & nc \\
\hline Myrcia cf. amazonica DC. & Preferencial de FODS & $\mathrm{nc}$ \\
\hline Myrcia cf. freyreissiana (O. Berg) Kiaersk. & Típica de FODM & MR 480 \\
\hline Myrcia sosias D. Legrand & Ampla & MR 500 \\
\hline Myrcia splendens (Sw.) DC. & Indeterminada & MR 194 \\
\hline cf. Neomitranthes glomerata (D. Legrand) D. Legrand & Ampla & nc \\
\hline Pimenta pseudocaryophyllus (Gomes) Landrum & Ampla & $\mathrm{nc}$ \\
\hline Plinia brachybotrya (D. Legrand) Sobral & Típica de FODM & MR 506 \\
\hline Myrtaceae 1 & Indeterminada & nc \\
\hline Myrtaceae 2 & Indeterminada & $\mathrm{nc}$ \\
\hline \multicolumn{3}{|l|}{ OLEACEAE } \\
\hline Chionanthus filiformis (Vell.) P.S. Green & Ampla & MR 587 \\
\hline \multicolumn{3}{|l|}{ POLYGONACEAE } \\
\hline Coccoloba sp. & Indeterminada & nc \\
\hline \multicolumn{3}{|l|}{ PROTEACEAE } \\
\hline Roupala brasiliensis Klotzsch & Ampla & MR 691 \\
\hline Roupala consimilis Mez ex Taub. & Típica de FODM & nc \\
\hline \multicolumn{3}{|l|}{ ROSACEAE } \\
\hline Prunus sellowii Koehne & Ampla & MR 158 \\
\hline \multicolumn{3}{|l|}{ RUBIACEAE } \\
\hline Cordiera concolor (Cham.) Kuntze & Ampla & MR 367 \\
\hline Posoqueria latifolia (Rudge) Roem. \& Schult. & Preferencial de FODS & MR 481 \\
\hline Psychotria suterella Müll. Arg. & Ampla & MR 22 \\
\hline Psychotria vellosiana Benth. & Ampla & MR 105 \\
\hline Rudgea gardenioides (Cham.) Müll. Arg. & Típica de FODM & MR 637 \\
\hline Rudgea jasminoides (Cham.) Müll. Arg. & Ampla & MR 465 \\
\hline \multicolumn{3}{|l|}{ RUTACEAE } \\
\hline Esenbeckia grandiflora Mart. & Ampla & MR 214 \\
\hline \multicolumn{3}{|l|}{ SALICACEAE } \\
\hline Casearia decandra Jacq. & Ampla & MR 391 \\
\hline Casearia obliqua Spreng. & Ampla & $\mathrm{nc}$ \\
\hline Casearia sylvestris $\mathrm{Sw}$. & Ampla & MR 423 \\
\hline \multicolumn{3}{|l|}{ SAPINDACEAE } \\
\hline Allophyllus sp. & Indeterminada & MR 210 \\
\hline Cupania vernalis Cambess. & Preferencial de FOM & MR 138 \\
\hline Matayba cristae R. Reitz & Típica de FODM & MR 51 \\
\hline \multicolumn{3}{|l|}{ SAPOTACEAE } \\
\hline Chrysophyllum viride Mart. \& Eichl. & Preferencial de FODS & MR 392 \\
\hline
\end{tabular}


Tabela 2 (continuação)

\begin{tabular}{|c|c|c|}
\hline Família/Espécie & Distribuição & $\mathrm{N}^{\mathrm{o}}$ de coleta \\
\hline \multicolumn{3}{|l|}{ SOLANACEAE } \\
\hline Aureliana fasciculata Sendt. & Ampla & MR 41 \\
\hline \multicolumn{3}{|l|}{ THEACEAE } \\
\hline Gordonia fruticosa (Schrad.) H. Keng. & Ampla & MR 89 \\
\hline \multicolumn{3}{|l|}{ INDETERMINADAS } \\
\hline Morfoespécie 1 & Indeterminada & $\mathrm{nc}$ \\
\hline Morfoespécie 2 & Indeterminada & nc \\
\hline Morfoespécie 3 & Indeterminada & $\mathrm{nc}$ \\
\hline
\end{tabular}

Melastomataceae e Sapindaceae (3 espécies cada). Estas sete famílias juntas representam $61 \%$ da riqueza das espécies amostradas.

Foram amostradas quatro espécies presentes na lista vermelha de espécies em extinção do Estado do Paraná (Hatschbach \& Ziller 1995). São elas: Ocotea catharinensis (maior área basal na amostra), Ocotea odorifera e Calyptranthes pileata na categoria "rara" e Neomitranthes glomerata na categoria "em perigo". Ocotea catharinensis e O. odorifera ocorrem nos outros estados da região sul e também no sudeste (Baitello 2003), sendo que no Paraná a primeira apresenta uma distribuição ampla e a segunda ocorre preferencialmente em áreas de Floresta Ombrófila Mista. Calyptranthes pileata é uma espécie bastante rara, ocorre principalmente nas partes mais altas da mata pluvial, e no Estado de Santa Catarina sua distribuição limita-se entre 800 e 1.000 m s.n.m. (Legrand \& Klein 1971), no Paraná pode ser considerada típica da Floresta Ombrófila Densa Montana.

Das espécies amostradas, 15 (17,6\% do total) não puderam ser classificadas quanto a sua distribuição geográfica. Dentre as outras 70 espécies (82,4\%), 37 (52,8\% deste percentual) foram consideradas como de distribuição ampla, $16(22,9 \%)$ como típicas de Floresta Ombrófila Densa Montana, 10 (14,3\%) como preferenciais de Floresta Ombrófila Mista, 7 (10,0\%) como preferenciais de Floresta Ombrófila Densa
Submontana. As espécies tidas como típicas de Floresta Ombrófila Densa Montana são espécies que apresentam distribuição bastante restrita no Estado do Paraná, geralmente amostradas apenas nos municípios que margeiam a Serra do Mar (Quatro Barras, Piraquara, São José dos Pinhais) e nas serras dos municípios de Morretes e Guaratuba, e de um modo geral apresentam poucas coletas.

Os valores de similaridade (Sørensen) indicam que a vegetação amostrada nos Mananciais da Serra é mais semelhante às áreas amostradas a $1000 \mathrm{~m}$ s.n.m. na Serra da Prata (Blum 2006), no Morro do Canal (Lacerda 1999) e nas cotas 800 e 900 da referida serra, com 43,70; 40,96 e 42,22\% de similaridade, respectivamente. As maiores similaridades entre este e os estudos comparados estão expressas na tabela 3 .

Apesar de situadas na vertente atlântica de um outro trecho da Serra do Mar, as áreas situadas na Serra da Prata, em altitudes equivalente a deste estudo, apresentaram as maiores similaridades. Este fato está de acordo com a constatação realizada por Klein (1984), de que os agrupamentos altitudinais da Floresta Ombrófila Densa no sul do Brasil estão ligados pelos mesmos elementos componentes. Segundo o mesmo autor, de acordo com os diferentes estágios de sucessão e das condições edáficas locais ocorrem diferentes tipos de associações, onde as freqüências e densidades das espécies variam.

Tabela 3. Os dez maiores valores de simaridade (índice de Sorensen) entre a área amostrada nos Mananciais da Serra e os 22 estudos comparados. As siglas representam os estudos listados na tabela 1. FOM = Floresta Ombrófila Mista; FOD = Floresta Ombrófila Densa; $\mathrm{M}=$ Montana; $\mathrm{S}=$ Submontana; “"” = transição.

\begin{tabular}{|c|c|c|c|c|c|c|c|c|c|c|c|}
\hline & 6 FODM & 2 & FOM/FOD & 7 FODM & 5 FODM & $3 \mathrm{FOM} / \mathrm{FOD}$ & 4 FODM & $8 \mathrm{FODM} / \mathrm{S}$ & 9 FODS & $15 \mathrm{FOM}$ & $11 \mathrm{FOM}$ \\
\hline $\begin{array}{l}1 \mathrm{FOM} / \\
\mathrm{FOD}\end{array}$ & 43,70 & & 42,20 & 40,96 & 30,88 & 26,56 & 25,00 & 18,72 & 18,72 & 18,10 & 17,39 \\
\hline
\end{tabular}


Com relação aos estudos realizados na transição entre as Florestas Ombrófilas Densa e Mista na Serra do Mar paranaense, a similaridade foi relativamente alta com a área situada no Morro do Canal (Lacerda 1999). No entanto, grande parte das diferenças florísticas deram-se, provavelmente, em virtude das diferenças sucessionais entre estas duas áreas, já que encontram-se geograficamente muito próximas e em altitudes similares (ver discussão sobre a estrutura mais adiante). Quanto ao estudo realizado no Morro do Anhangava (Roderjan 1994), segundo o próprio autor, o esforço desprendido na amostragem do patamar altimétrico montano foi insuficiente, resultando numa lista parcial da flora daquele lugar.

Na figura 2 estão representados três dendrogramas de similaridades (Sorensen) gerados a partir da análise de UPGMA. Optou-se pela análise separada dos dados para evidenciar as diferenças entre as formações de Floresta Ombrófila Densa Montana da vertente atlântica e planáltica da Serra do Mar paranaense. No primeiro dendrograma (figura 2A), onde não foram incluídos os dados dos estudos realizados em áreas de transição entre a FOD e áreas de FOM, é possível a identificação de dois grupos. O primeiro é formado pelas áreas amostradas no domínio de FOM e o segundo grupo é formado pelas áreas de FODM, FODS e FODT. Isso mostra que apesar de heterogêneas, FOD e FOM apresentam unidades florísticas diferenciadas.

No segundo dendrograma (figura 2B), onde não foram incluídos os dados dos estudos realizados em áreas de FODM na vertente atlântica da Serra do Mar paranaense, também verifica-se a formação de dois grupos. O primeiro seria formado pelas áreas de FODS e FODT, e o segundo pelas áreas situadas na transição entre a FOM e FODM mais as áreas de FOM. Tal fato deve-se à relativa abundância de espécies típicas de FOM que estão presentes nestas áreas de transição, o que foi verificado na análise da distribuição das espécies amostradas neste estudo.

No terceiro dendrograma (figura 2C), onde todos os dados foram incluídos, evidencia-se a formação de três grupos. O primeiro formado pelas áreas de FODS e FODT, o segundo pelas áreas de FOM, e o terceiro grupo, que ficou agrupado com o de FOM, é formado pelas áreas de FODM de ambas as vertentes da Serra do Mar paranaense.

A presença do estudo realizado na reserva de Guaricana (4 FODM) no grupo de FODS e FODT pode ser explicada quando analisada sua composição florística. Apesar de estar no patamar altimétrico montano proposto pelo IBGE (1992), a área amostrada situou-se em altitudes que variaram de 500 a 800 m s.n.m., portanto, situada em uma área de transição entre a FODM e FODS (Blum 2006), onde a influência dos elementos componentes desta última formação é mais pronunciada. Algumas espécies preferenciais de FODS na Serra do Mar paranaense que foram amostradas nesta área são Cecropia pachystachya Trécul, Bathysa meridionalis L.B. Sm. \& Downs, Copaifera trapezifolia Hayne, Cupania oblongifolia Mart., Hieronyma alchorneoides Allem., dentre outras (dados obtidos a partir da matriz de presença ou ausência das espécies amostradas nas áreas referidas na tabela 1).

Cabe ressaltar que a área amostrada em Camanducaia, MG (10 FODM), apesar de geograficamente distante das formações montanas do Estado do Paraná (Área 10, figura 1), ficou agrupada junto com estas. França \& Stehmann (2004) realizaram comparações utilizando o índice de similaridade de Jaccard e verificaram que a maior similaridade foi de 7,08 com uma área situada no mesmo estado. O índice de similaridade de Jaccard de Camanducaia com o presente estudo é de 7,74, com o Morro do Canal é de 9,36 e com a cota de 1.100 m s.n.m. na Serra da Prata igual a 10,74. São exemplos de espécies comuns entre esta área e a dos Mananciais da Serra Ilex paraguariensis, I. taubertiana, Schefflera angustissima, Weinmannia paulliniifolia, Alsophila setosa, Dicksonia sellowiana, Myrceugenia miersiana, Pimenta pseudocaryophyllus, Psychotria vellosiana, Gordonia fruticosa, dentre outras. Quando analisada a composição desta área é possível verificar que trata-se de uma região composta por elementos de FOM e FOD, e uma análise mais ampla poderia verificar ou não o caráter disjunto destas áreas, o que, à primeira vista, está de acordo com a hipótese dispersionista dos elementos australantárticos e andinos proposta por Rambo (1953).

Estrutura - Fisionomicamente a vegetação nos Mananciais da Serra é caracterizada por um estrato superior, em média com árvores de até $20 \mathrm{~m}$, onde destacam-se Ocotea catharinensis, Cryptocarya aschersoniana, Alchornea triplinervia, Ilex dumosa e Ocotea pulchella; por um estrato intermediário que concentra a maior densidade e diversidade, com árvores entre 4 e $12 \mathrm{~m}$ de altura, onde destacam-se Cordiera concolor, Eugenia sp. 1, Sorocea bonplandii, Myrcia cf. freyreissiana, Aspidosperma 


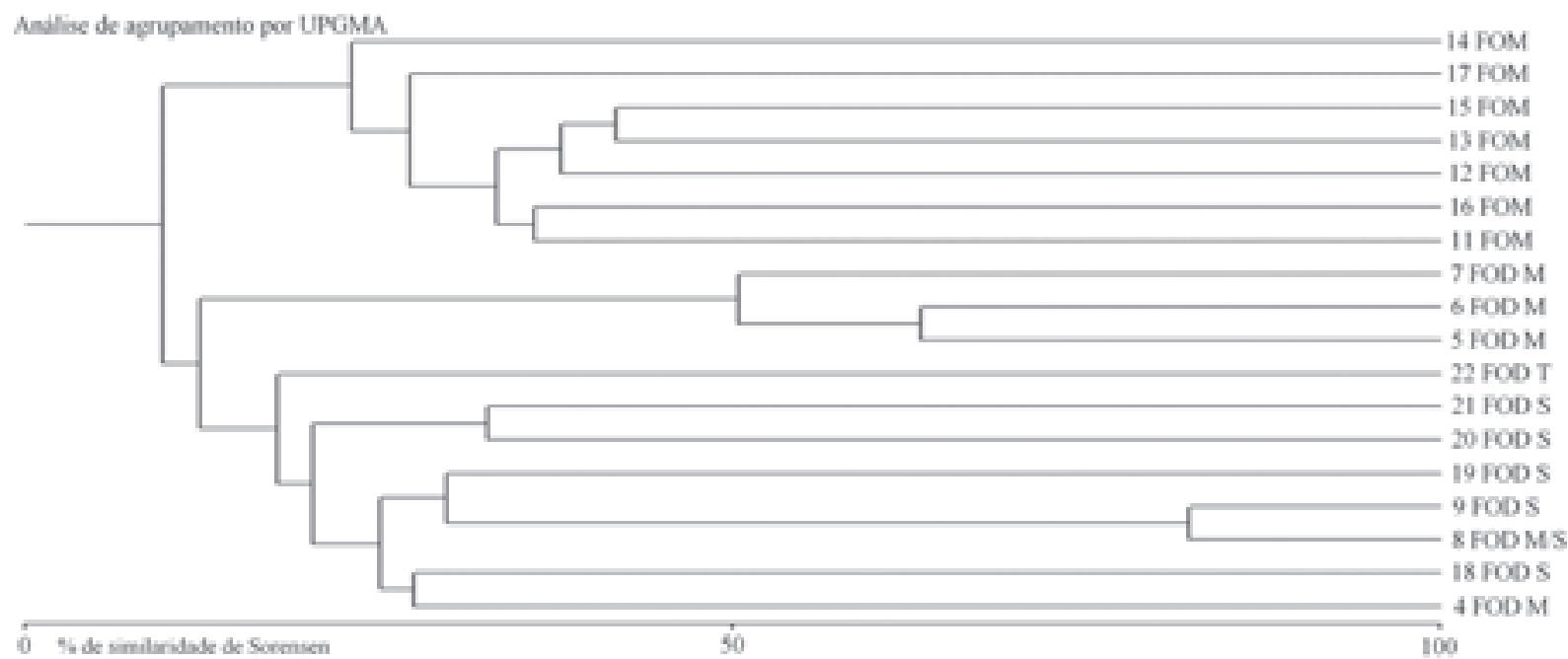

Anilise de agremenso por UTCMA


Figura 2. Dendrogramas gerados por análise de agrupamento (UPGMA) a partir dos coeficientes de similaridade de Sorensen, os códigos correspondem aos estudos listados na tabela 1. No dendrograma A não foram incluídas as áreas amostradas na transição entre a FOD e FOM, no dendrograma B não foram incluídas as áreas amostradas em FODM na vertente atlântica da Serra do Mar paranaense, e no dendrograma $\mathrm{C}$ foram incluídas todas as áreas. FOM = Floresta Ombrófila Mista; FOD = Floresta Ombrófila Densa; $\mathrm{M}=$ Montana; $\mathrm{S}=$ Submontana; T = Terras Baixas; “/” = transição. 
pyricollum, Ocotea elegans e indivíduos mais senis de Alsophila setosa; e um estrato inferior, com indivíduos menores que $4 \mathrm{~m}$, onde predominam Alsophila setosa, Cyathea phalerata, Geonoma schottiana e Mollinedia spp. Um perfil esquemático da vegetação é apresentado na figura 3 .

A densidade obtida para esta comunidade foi de 2.203 indivíduos $\mathrm{ha}^{-1}$. Este valor é próximo aos encontrados, utilizando o mesmo critério de inclusão, em uma área de transição entre as Florestas Ombrófila Densa Montana e Altomontana (Roderjan 1994) e em uma área de Floresta Ombrófila Densa Montana em estágio avançado de sucessão (Lacerda 1999), onde obtiveram 2.169 e 2.644 indivíduos ha ${ }^{-1}$, respectivamente. Ambos estudos foram realizados em áreas situadas na região de transição entre as Florestas Ombrófilas Densa e Mista em altitudes similares a deste estudo. O valor também se assemelha aos 2.335 indivíduos ha $^{-1}$ registrados em uma formação madura de Floresta Ombrófila Densa Montana no Estado de São Paulo (Tabarelli \& Mantovani 1999). As espécies mais abundantes na amostra foram
Alsophila setosa (14,1\% do total), Cyathea phalerata $(8,59 \%)$, Cordiera concolor $(7,29 \%)$, Eugenia sp. 1 (6,48\%) e Cryptocarya aschersoniana $(4,38 \%)$.

Alsophila setosa não se destacou em nenhum outro estudo analisado. No entanto, em um estudo sobre a sua ecologia, Schmitt \& Windisch (2005) ressaltam que é muito comum esta espécie formar densos aglomerados no interior de certas formações secundárias. Tal fato decorreria da sua eficiente reprodução vegetativa, a partir de ramificações estoloníferas, que lhe confere uma eficiente capacidade de ocupar novos nichos. Isto foi verificado neste estudo, tanto em campo como no cálculo do índice de agrupamento. Dentre as espécies mais abundantes, outras que também apresentaram distribuição agregada foram Myrcia cf. freyreissiana, Schefflera angustissima, Rudgea gardenioides, Mollinedia uleana e Roupala brasiliensis.

A espécie mais freqüente na área amostrada foi Cyathea phalerata, presente em $71,4 \%$ das parcelas.

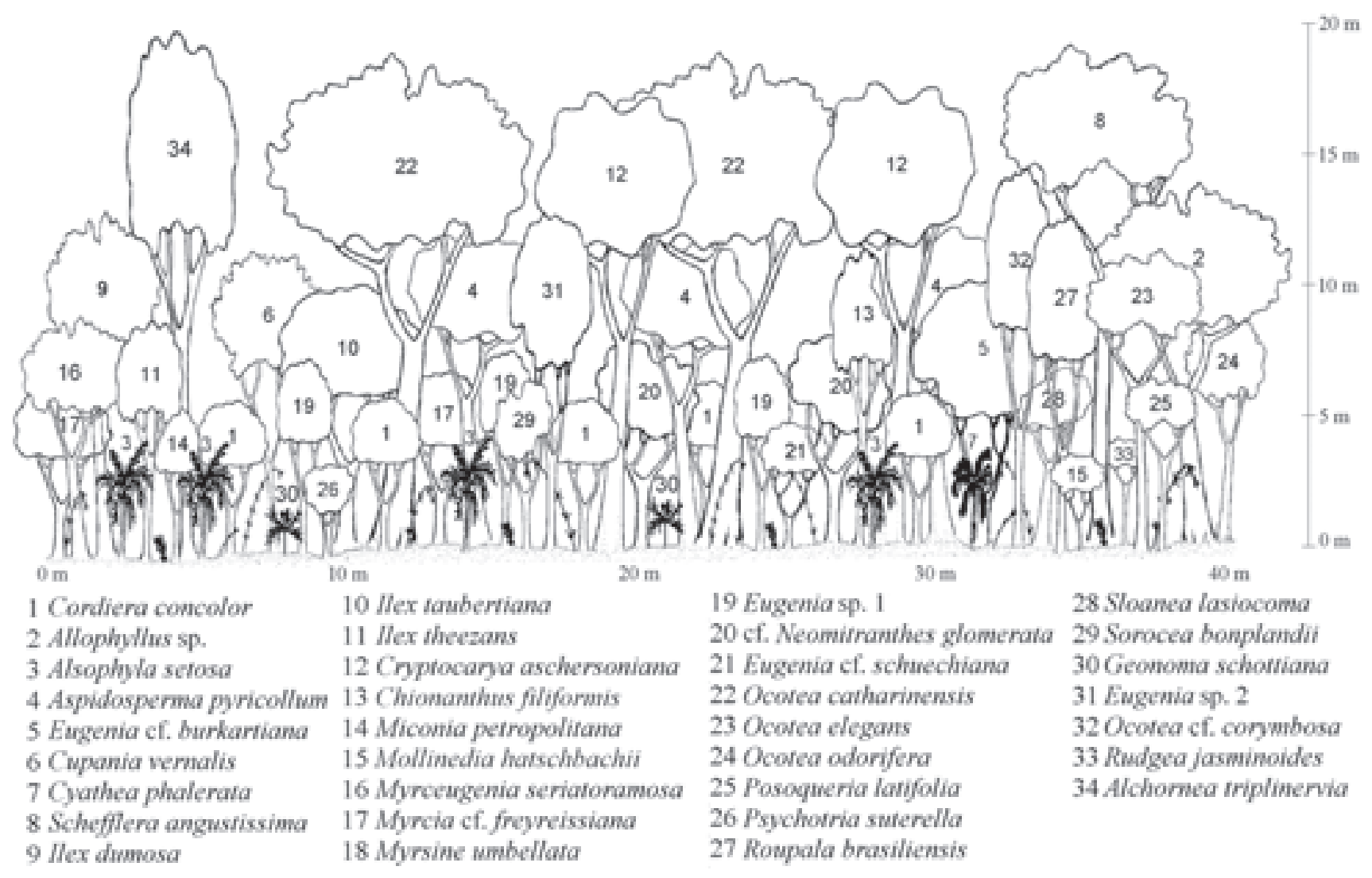

Figura 3. Perfil esquemático da vegetação amostrada em 0,28 ha de uma área situada na transição entre as Florestas Ombrófilas Densa Montana e Mista nos Mananciais da Serra, onde foram retratados todos os indivíduos de 4 parcelas $(5 \times 10 \mathrm{~m})$ em escala segundo as suas alturas. 
Esta é uma espécie característica e freqüente no subbosque de florestas em avançado estágio sucessional das encostas do Vale do Itajaí (Klein 1980). Na seqüência destacaram-se Cryptocarya aschersoniana $(60,7 \%)$, Cordiera concolor (60,7 \%), Eugenia sp. 1 $(57,1 \%)$ e Sorocea bonplandii $(57,1 \%)$.
Cryptocarya aschersoniana foi a espécie mais freqüente ao longo de todo o gradiente altitudinal (4001.100 m s.n.m.) na encosta atlântica da Serra da Prata (Blum 2006). Os resultados de todos os parâmetros fitossociológicos analisados para estas espécies encontram-se na tabela 4.

Tabela 4. Parâmetros fitossociológicos das espécies amostradas em 0,28 ha de uma área situada na transição entre as Florestas Ombrófilas Densa Montana e Mista nos Mananciais da Serra, dispostas em ordem decrescente de VI. Ni: número de indivíduos amostrados; DA: densidade absoluta (indiv $/ \mathrm{ha}^{-1}$ ); DR: densidade relativa (\%); FA: freqüência absoluta (\%); FR: freqüência relativa (\%); DoA: dominância absoluta $\left(\mathrm{m}^{2} / \mathrm{ha}^{-1}\right)$; DoR: dominância relativa $(\%)$; VI: valor de importância.

\begin{tabular}{|c|c|c|c|c|c|c|c|c|}
\hline Espécie & ni & $\begin{array}{c}\text { DA } \\
\text { (indiv/ha }{ }^{-1} \text { ) }\end{array}$ & $\begin{array}{l}\text { DR } \\
(\%)\end{array}$ & $\begin{array}{c}\text { FA } \\
\left(\mathrm{m}^{2} \mathrm{ha}^{-1}\right)\end{array}$ & $\begin{array}{l}\text { FR } \\
(\%)\end{array}$ & $\begin{array}{c}\text { DoA } \\
(\%)\end{array}$ & $\begin{array}{l}\text { DoR } \\
(\%)\end{array}$ & VI \\
\hline Alsophyla setosa & 87 & 310,71 & 14,10 & 53,57 & 3,95 & 2,856 & 6,99 & 8,35 \\
\hline Ocotea catharinensis & 21 & 75,00 & 3,40 & 53,57 & 3,95 & 4,532 & 11,09 & 6,15 \\
\hline Cyathea phalerata & 53 & 189,29 & 8,59 & 71,43 & 5,26 & 1,844 & 4,51 & 6,12 \\
\hline Cryptocarya aschersoniana & 27 & 96,43 & 4,38 & 60,71 & 4,47 & 2,236 & 5,47 & 4,77 \\
\hline Cordiera concolor & 45 & 160,71 & 7,29 & 60,71 & 4,47 & 0,624 & 1,53 & 4,43 \\
\hline Eugenia sp. 1 & 40 & 142,86 & 6,48 & 57,14 & 4,21 & 0,936 & 2,29 & 4,33 \\
\hline Sorocea bonplandii & 22 & 78,57 & 3,57 & 57,14 & 4,21 & 0,552 & 1,35 & 3,04 \\
\hline Ilex dumosa & 10 & 35,71 & 1,62 & 32,14 & 2,37 & 1,316 & 3,22 & 2,40 \\
\hline Alchornea triplinervia & 4 & 14,29 & 0,65 & 14,29 & 1,05 & 2,232 & 5,46 & 2,39 \\
\hline Myrcia cf. freyreissiana & 19 & 67,86 & 3,08 & 32,14 & 2,37 & 0,408 & 1,00 & 2,15 \\
\hline Aspidosperma pyricollum & 15 & 53,57 & 2,43 & 32,14 & 2,37 & 0,620 & 1,52 & 2,11 \\
\hline Ocotea elegans & 12 & 42,86 & 1,94 & 28,57 & 2,11 & 0,704 & 1,72 & 1,92 \\
\hline cf. Neomitranthes glomerata & 9 & 32,14 & 1,46 & 28,57 & 2,11 & 0,820 & 2,01 & 1,86 \\
\hline Cupania vernalis & 11 & 39,29 & 1,78 & 32,14 & 2,37 & 0,576 & 1,41 & 1,85 \\
\hline Ocotea pulchella & 5 & 17,86 & 0,81 & 17,86 & 1,32 & 1,312 & 3,21 & 1,78 \\
\hline Weinmannia paulliinifollia & 6 & 21,43 & 0,97 & 21,43 & 1,58 & 1,020 & 2,50 & 1,68 \\
\hline Schefflera angustissima & 7 & 25,00 & 1,13 & 17,86 & 1,32 & 0,964 & 2,36 & 1,60 \\
\hline Ocotea cf. corymbosa & 4 & 14,29 & 0,65 & 14,29 & 1,05 & 1,236 & 3,03 & 1,58 \\
\hline Ilex taubertiana & 10 & 35,71 & 1,62 & 25,00 & 1,84 & 0,460 & 1,13 & 1,53 \\
\hline Morfoespécie 1 & 1 & 3,57 & 0,16 & 3,57 & 0,26 & 1,668 & 4,08 & 1,50 \\
\hline Ilex theezans & 10 & 35,71 & 1,62 & 28,57 & 2,11 & 0,296 & 0,72 & 1,48 \\
\hline Ocotea odorifera & 9 & 32,14 & 1,46 & 28,57 & 2,11 & 0,324 & 0,79 & 1,45 \\
\hline Myrceugenia seriatoramosa & 8 & 28,57 & 1,30 & 28,57 & 2,11 & 0,316 & 0,77 & 1,39 \\
\hline Gordonia fruticosa & 7 & 25,00 & 1,13 & 21,43 & 1,58 & 0,576 & 1,41 & 1,37 \\
\hline Geonoma schottiana & 11 & 39,29 & 1,78 & 28,57 & 2,11 & 0,084 & 0,21 & 1,37 \\
\hline Sloanea lasiocoma & 8 & 28,57 & 1,30 & 25,00 & 1,84 & 0,292 & 0,71 & 1,28 \\
\hline Ormosia arborea & 4 & 14,29 & 0,65 & 14,29 & 1,05 & 0,784 & 1,92 & 1,21 \\
\hline Chionanthus filiformis & 7 & 25,00 & 1,13 & 21,43 & 1,58 & 0,368 & 0,90 & 1,20 \\
\hline Nectandra puberula & 3 & 10,71 & 0,49 & 10,71 & 0,79 & 0,896 & 2,19 & 1,16 \\
\hline Psychotria vellosiana & 7 & 25,00 & 1,13 & 21,43 & 1,58 & 0,256 & 0,63 & 1,11 \\
\hline Cinnamomum pseudoglaziovii & 2 & 7,14 & 0,32 & 7,14 & 0,53 & 0,980 & 2,40 & 1,08 \\
\hline Rudgea gardenioides & 7 & 25,00 & 1,13 & 17,86 & 1,32 & 0,312 & 0,76 & 1,07 \\
\hline Eugenia $\mathrm{cf}$. burkartiana & 6 & 21,43 & 0,97 & 17,86 & 1,32 & 0,324 & 0,79 & 1,03 \\
\hline Cabralea canjerana & 1 & 3,57 & 0,16 & 3,57 & 0,26 & 1,004 & 2,46 & 0,96 \\
\hline Maytenus robusta & 2 & 7,14 & 0,32 & 7,14 & 0,53 & 0,792 & 1,94 & 0,93 \\
\hline Myrcia cf. amazonica & 4 & 14,29 & 0,65 & 14,29 & 1,05 & 0,376 & 0,92 & 0,87 \\
\hline Posoqueria latifolia & 5 & 17,86 & 0,81 & 17,86 & 1,32 & 0,192 & 0,47 & 0,87 \\
\hline Mollinedia uleana & 7 & 25,00 & 1,13 & 17,86 & 1,32 & 0,028 & 0,07 & 0,84 \\
\hline Myrsine umbellata & 4 & 14,29 & 0,65 & 14,29 & 1,05 & 0,320 & 0,78 & 0,83 \\
\hline Eugenia pleurantha & 4 & 14,29 & 0,65 & 7,14 & 0,53 & 0,536 & 1,31 & 0,83 \\
\hline Roupala brasiliensis & 5 & 17,86 & 0,81 & 10,71 & 0,79 & 0,356 & 0,87 & 0,82 \\
\hline Byrsonima ligustrifolia & 5 & 17,86 & 0,81 & 17,86 & 1,32 & 0,136 & 0,33 & 0,82 \\
\hline
\end{tabular}


Tabela 4 (continuação)

\begin{tabular}{|c|c|c|c|c|c|c|c|c|}
\hline Espécie & ni & $\begin{array}{c}\mathrm{DA} \\
\text { (indiv/ha }{ }^{-1} \text { ) }\end{array}$ & $\begin{array}{l}\text { DR } \\
(\%)\end{array}$ & $\begin{array}{c}\text { FA } \\
\left(\mathrm{m}^{2} \mathrm{ha}^{-1}\right)\end{array}$ & $\begin{array}{l}\text { FR } \\
(\%)\end{array}$ & $\begin{array}{c}\text { DoA } \\
(\%)\end{array}$ & $\begin{array}{c}\text { DoR } \\
(\%)\end{array}$ & VI \\
\hline Guatteria australis & 5 & 17,86 & 0,81 & 14,29 & 1,05 & 0,208 & 0,51 & 0,79 \\
\hline Calyptranthes cf. pileata & 5 & 17,86 & 0,81 & 17,86 & 1,32 & 0,064 & 0,16 & 0,76 \\
\hline cf. Myrceugenia venosa & 4 & 14,29 & 0,65 & 14,29 & 1,05 & 0,208 & 0,51 & 0,74 \\
\hline Miconia petropolitana & 5 & 17,86 & 0,81 & 14,29 & 1,05 & 0,044 & 0,11 & 0,66 \\
\hline Eugenia sp. 2 & 3 & 10,71 & 0,49 & 10,71 & 0,79 & 0,256 & 0,63 & 0,64 \\
\hline Mollinedia hatschbachii & 4 & 14,29 & 0,65 & 14,29 & 1,05 & 0,016 & 0,04 & 0,58 \\
\hline Pimenta pseudocaryophyllus & 2 & 7,14 & 0,32 & 3,57 & 0,26 & 0,468 & 1,15 & 0,58 \\
\hline Myrcia sosias & 2 & 7,14 & 0,32 & 7,14 & 0,53 & 0,308 & 0,75 & 0,53 \\
\hline Cinnamomum cf. triplinerve & 2 & 7,14 & 0,32 & 7,14 & 0,53 & 0,300 & 0,73 & 0,53 \\
\hline Allophyllus sp. & 3 & 10,71 & 0,49 & 7,14 & 0,53 & 0,232 & 0,57 & 0,53 \\
\hline Morfoespécie 2 & 1 & 3,57 & 0,16 & 3,57 & 0,26 & 0,452 & 1,11 & 0,51 \\
\hline Prunus sellowii & 2 & 7,14 & 0,32 & 7,14 & 0,53 & 0,212 & 0,52 & 0,46 \\
\hline Matayba cristae & 3 & 10,71 & 0,49 & 7,14 & 0,53 & 0,080 & 0,20 & 0,41 \\
\hline Marlieria reitzii & 1 & 3,57 & 0,16 & 3,57 & 0,26 & 0,288 & 0,71 & 0,38 \\
\hline Dicksonia sellowiana & 2 & 7,14 & 0,32 & 3,57 & 0,26 & 0,208 & 0,51 & 0,36 \\
\hline Rudgea jasminoides & 3 & 10,71 & 0,49 & 7,14 & 0,53 & 0,016 & 0,04 & 0,35 \\
\hline Coccoloba sp. & 1 & 3,57 & 0,16 & 3,57 & 0,26 & 0,228 & 0,56 & 0,33 \\
\hline Eugenia kleinii & 2 & 7,14 & 0,32 & 7,14 & 0,53 & 0,028 & 0,07 & 0,31 \\
\hline Roupala consimilis & 2 & 7,14 & 0,32 & 7,14 & 0,53 & 0,024 & 0,06 & 0,30 \\
\hline Eugenia cf. schuechiana & 2 & 7,14 & 0,32 & 7,14 & 0,53 & 0,024 & 0,06 & 0,30 \\
\hline Miconia sellowiana & 2 & 7,14 & 0,32 & 7,14 & 0,53 & 0,016 & 0,04 & 0,30 \\
\hline Dalbergia frutescens & 2 & 7,14 & 0,32 & 7,14 & 0,53 & 0,016 & 0,04 & 0,30 \\
\hline Chrysophyllum viride & 2 & 7,14 & 0,32 & 7,14 & 0,53 & 0,008 & 0,02 & 0,29 \\
\hline Psychotria suterella & 1 & 3,57 & 0,16 & 3,57 & 0,26 & 0,128 & 0,31 & 0,24 \\
\hline Myrcia splendens & 2 & 7,14 & 0,32 & 3,57 & 0,26 & 0,056 & 0,14 & 0,24 \\
\hline Myrtaceae 2 & 1 & 3,57 & 0,16 & 3,57 & 0,26 & 0,116 & 0,28 & 0,23 \\
\hline Eugenia handroana & 2 & 7,14 & 0,32 & 3,57 & 0,26 & 0,020 & 0,05 & 0,21 \\
\hline Aureliana fasciculata & 2 & 7,14 & 0,32 & 3,57 & 0,26 & 0,016 & 0,04 & 0,21 \\
\hline Ilex paraguariensis & 1 & 3,57 & 0,16 & 3,57 & 0,26 & 0,056 & 0,14 & 0,19 \\
\hline Plinia brachybotrya & 1 & 3,57 & 0,16 & 3,57 & 0,26 & 0,044 & 0,11 & 0,18 \\
\hline Morfoespécie 3 & 1 & 3,57 & 0,16 & 3,57 & 0,26 & 0,044 & 0,11 & 0,18 \\
\hline Myrtaceae 1 & 1 & 3,57 & 0,16 & 3,57 & 0,26 & 0,028 & 0,07 & 0,16 \\
\hline Myrceugenia cf. ovalifolia & 1 & 3,57 & 0,16 & 3,57 & 0,26 & 0,028 & 0,07 & 0,16 \\
\hline Casearia sylvestris & 1 & 3,57 & 0,16 & 3,57 & 0,26 & 0,028 & 0,07 & 0,16 \\
\hline Eugenia sp. 3 & 1 & 3,57 & 0,16 & 3,57 & 0,26 & 0,028 & 0,07 & 0,16 \\
\hline Ocotea glaziovii & 1 & 3,57 & 0,16 & 3,57 & 0,26 & 0,024 & 0,06 & 0,16 \\
\hline Casearia obliqua & 1 & 3,57 & 0,16 & 3,57 & 0,26 & 0,016 & 0,04 & 0,15 \\
\hline Lamanonia speciosa & 1 & 3,57 & 0,16 & 3,57 & 0,26 & 0,012 & 0,03 & 0,15 \\
\hline Esenbeckia grandiflora & 1 & 3,57 & 0,16 & 3,57 & 0,26 & 0,008 & 0,02 & 0,15 \\
\hline Endlicheria paniculata & 1 & 3,57 & 0,16 & 3,57 & 0,26 & 0,004 & 0,01 & 0,14 \\
\hline Sloanea sp. & 1 & 3,57 & 0,16 & 3,57 & 0,26 & 0,004 & 0,01 & 0,14 \\
\hline Casearia decandra & 1 & 3,57 & 0,16 & 3,57 & 0,26 & 0,004 & 0,01 & 0,14 \\
\hline Leandra barbinervis & 1 & 3,57 & 0,16 & 3,57 & 0,26 & 0,004 & 0,01 & 0,14 \\
\hline Total & 617 & 2203,57 & 100 & 1357,14 & 100 & 40,852 & 100 & 100 \\
\hline
\end{tabular}

A área basal da comunidade estudada foi de $40,85 \mathrm{~m}^{2} \mathrm{ha}^{-1}$. Assim como o valor de densidade, este se assemelha, respectivamente, aos 41,3, 44,3 e $38,6 \mathrm{~m}^{2} \mathrm{ha}^{-1}$ encontrados por Roderjan (1994), Lacerda (1999) e Tabarelli \& Mantovani (1999), em suas respectivas áreas supracitadas. As espécies que apresentaram os maiores valores de dominância foram
Ocotea catharinensis (11,1\% do total), Alsophila setosa (7\%), Cryptocarya aschersoniana (5,5\%), Alchornea triplinervia $(5,5)$ e Cyathea phalerata $(4,5)$.

Do total das 85 espécies amostradas, 13 concentraram $50 \%$ do valor de importância (figura 4). Alsophila setosa foi a espécie mais importante na amostra (VI $=8,35)$, seguida por Ocotea 
catharinensis (VI = 6,15), Cyathea phalerata $(\mathrm{VI}=6,12)$, Cryptocarya aschersoniana $(\mathrm{VI}=4,77)$ e Cordiera concolor (VI $=4,43)$. Quanto às duas pteridófitas arborescentes, $A$. setosa não se destacou em nenhum dos estudos comparados, enquanto que C. phalerata figurou entre as espécies mais abundantes na Reserva de Guaricana (Schorn 1992). Ocotea catharinensis apresentou altos valores de importância nos estudos realizados em Quatro Barras (Roderjan 1994) e na Serra da Prata (Blum 2006). Cryptocarya aschersoniana e C. concolor também se destacaram nos patamares montanos e de transição para submontanos na Serra da Prata (Blum 2006). Ocotea catharinensis é a espécie mais importante nas encostas da Serra do Mar do sul do Brasil em estágios sucessionais avançados, seguida por $C$. aschersoniana e $O$. odorifera, esta última substituindo Sloanea guianensis Benth. em alguns trechos no Alto do Vale do Itajaí (Klein 1984).

As populações de Ocotea catharinensis, C. aschersoniana e C. concolor aparentemente estão em processo de regeneração na área de estudo, apresentando mais indivíduos nas classes de menor diâmetro com uma progressiva diminuição até as maiores classes (figura 5). Outras espécies que apresentaram este padrão foram Eugenia sp. 1, Sorocea bonplandii, Ilex dumosa, Myrcia cf. freyreissiana e Ocotea elegans. Por outro lado, a população de Alchornea triplinervia não está se regenerando, provavelmente, devido às condições de luminosidade no sub-bosque. Aparentemente, A. triplinervia está nesta comunidade como um relicto de um estágio sucessional anterior. No entanto, Klein (1984) sugere que esta espécie, juntamente com algumas outras caducifólias, representam na região da Floresta Ombrófila Densa relictos de um clima pretérito mais seco. Dentre as espécies mais importantes, Ocotea pulchella também apresentou este mesmo padrão.

A área situada no Morro do Canal (Lacerda 1999), apesar de geograficamente próxima aos Mananciais da Serra, apresentou diferenças estruturais significativas com relação a esta. As espécies de maior importância deste estudo não foram amostradas nos Mananciais da Serra, como é o caso de Nectandra lanceolata Nees e Miconia pusilliflora Naudin, ou ocorreram de forma esparsa, como por exemplo Psychotria vellosiana e Casearia sylvestris, sendo que estas duas últimas espécies são tidas como pioneiras. Outras espécies pioneiras que também ocorreram de forma pontual nos Mananciais da Serra foram Lamanonia speciosa e Prunus sellowii (Klein 1962, Klein \& Hatschbach 1962).

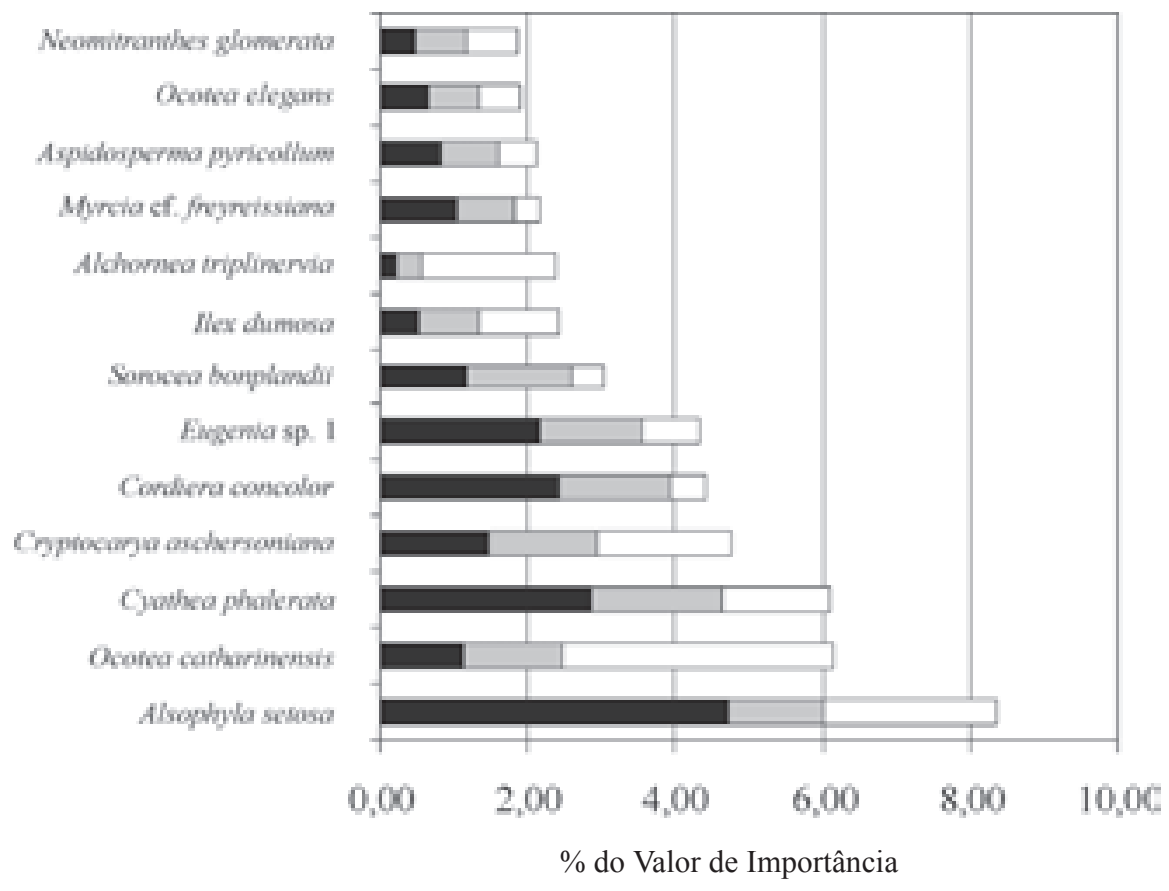

Figura 4. Valores relativos de densidade (DR), frequência (FR) e dominância (DoR) das 13 espécies que concentraram $50 \%$ do valor de importância na amostragem de 0,28 ha de uma área situada na transição entre as Florestas Ombrófilas Densa Montana e Mista nos Mananciais da Serra. ( $\mathbf{\square}=\mathrm{DR} ; \square=\mathrm{FR} ; \square=\mathrm{DoR})$. 

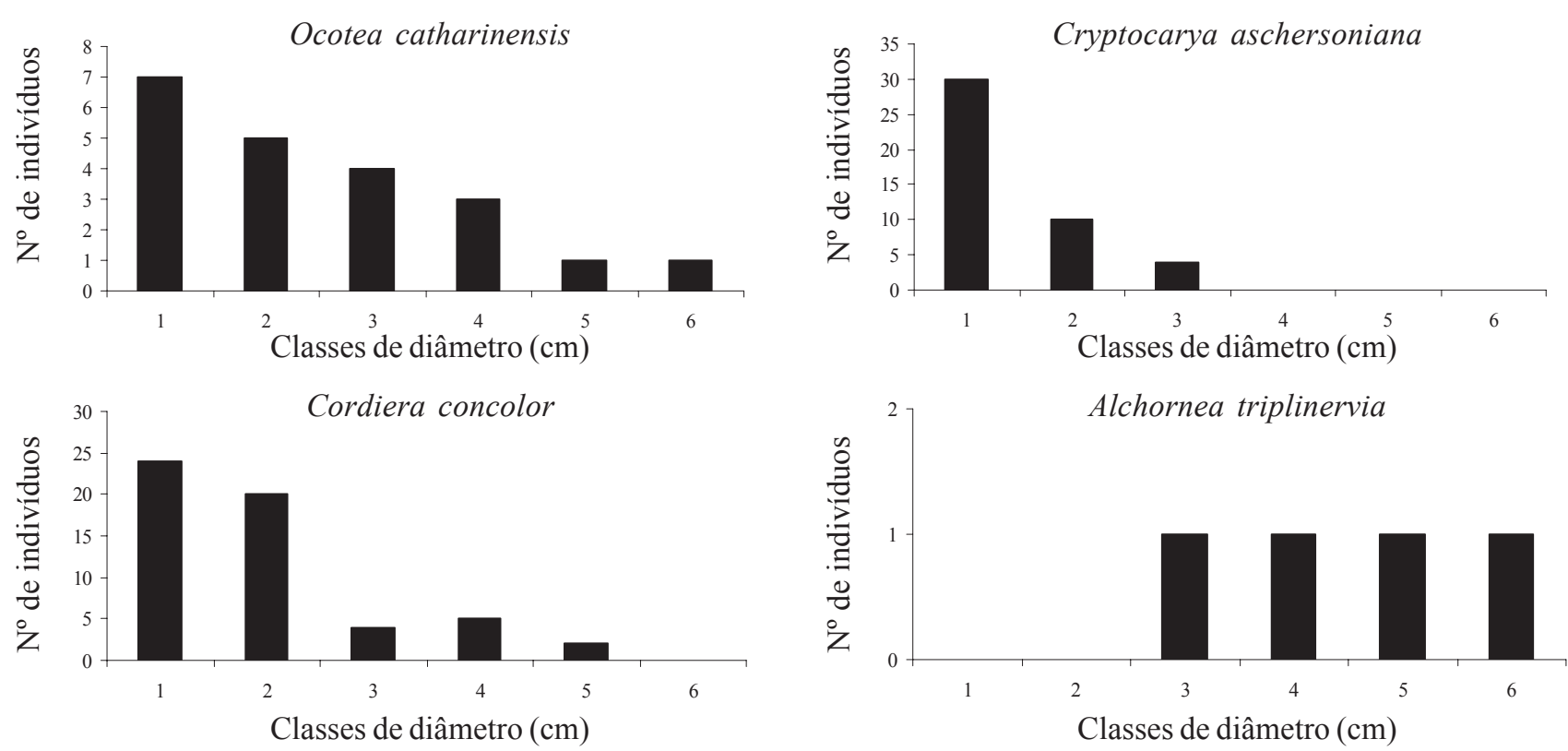

Figura 5. Distribuição das classes de DAP para algumas das espécies mais importantes na amostragem de 0,28 ha de uma área situada na transição entre as Florestas Ombrófilas Densa Montana e Mista nos Mananciais da Serra. As classes de DAP (exceto para Cordiera concolor) são: 1 - de 3,2 a 13,2; 2 - de 13,3 a 23,2; 3 - de 23,3 a 33,2; 4 - de 33,3 a 43,2; 5 - de 43,3 a 53,2; 6 - de 53,3 a 63,2. Para Cordiera concolor: 1 - de 3,2 a 5,2; 2 - de 5,3 a 7,2; 3 - de 7,3 a 9,2; 4-de 9,3 a 11,2; 5- de 11,3 a 13,2; 6 - de 13,3 a 15,2 .

As famílias que obtiveram os maiores valores de importância foram Lauraceae, Myrtaceae, Cyatheaceae, Rubiaceae, Aquifoliaceae e Moraceae, juntas concentraram $71 \%$ do valor de importância da amostra na comunidade estudada. A família Lauraceae destacou-se com altos valores de área basal, em virtude dos grandes DAPs apresentados pelos seus representantes. Myrtaceae foi a família que apresentou a maior densidade e freqüência, com destaque para as espécies Eugenia sp. 1 e Myrcia cf. freyreissiana. Estas duas famílias foram as mais importantes ao longo de todo o gradiente altitudinal na Serra da Prata (Blum 2006).

Tabarelli \& Mantovani (1999), estudando a sucessão vegetacional em Floresta Ombrófila Densa Montana no estado de São Paulo, verificaram que a importância das famílias Myrtaceae e Lauraceae aumenta com a maturidade da floresta e espécies dos gêneros Baccharis, Vernonia, Senna e Tibouchina, por exemplo, tendem a desaparecer ao longo da sucessão. Espécies destes táxons foram amostradas em áreas adjacentes à do presente estudo, geralmente ao longo das estradas e trilhas da região, e não foram registradas na amostra em foco (Reginato \& Goldenberg, dados não publicados).

A partir destas análises é possível constatar que a vegetação de FODM na Serra do Mar paranaense sofre uma marcada influencia em sua composição florística, tanto na vertente atlântica pelas espécies da FODS quanto na vertente planáltica por parte dos táxons da FOM. Na Serra do Mar paranaense, concomitantemente à presença dos táxons endêmicos da FODM, existe um gradiente transicional entre as floras de FOM e FODS. Isto ocorre porque na área de contato com a FOM, além das espécies de ampla distribuição, há um grande número de táxons típicos desta formação juntamente com os exclusivos da FODM, e um número reduzido de táxons típicos da FODS. Este quadro, aparentemente, tende a ir gradualmente se invertendo, pois o inverso é válido para as áreas de contato entre a FODM e a FODS. A substituição dos táxons ao longo deste gradiente de condições abióticas provavelmente deve ser influenciada pelo gradiente climático da região (transição de Cfa para $\mathrm{Cfb}$ ).

Este fato é verificado nas observações de campo realizadas por Rambo (1953) nos Aparados da Serra (RS). O autor referindo-se as matas do planalto (FOM) e das encostas dos Aparados (FOD) ressalta que a associação dos elementos florísticos destes é tão íntima, que as espécies de um contingente podem servir ao botânico como indicadores da proximidade do outro. Este mesmo autor destaca que o aparecimento de I. paraguariensis, fora da área dos 
pinhais, é sempre indício da vizinhança desta formação, o que vale para outras espécies também. Segundo este autor, existe um limite sistemático bem definido na subida dos Aparados, onde nota-se a rápida diluição do elemento puramente tropical à medida que se sobe a serra.

Dentre as 20 espécies com os maiores valores de importância (VI) na amostra, 13 apresentam distribuição ampla, três são típicas de FODM, duas são preferenciais de FOM e as outras duas não foram determinadas. Este quadro é um indício de que a influência das espécies de FOM sobre as de FODM na vertente planáltica não se restringe só à composição, mas também à estrutura desta comunidade. Quanto às espécies consideradas típicas de FODM na serra do mar paranaense, a maioria apresentou poucos indivíduos amostrados, no entanto três espécies apareceram entre as mais importantes, a saber: Myrcia cf. freyreissiana (19 indivíduos), Schefflera angustissima (7) e Ilex taubertiana (10).

Os trabalhos de Oliveira Filho \& Fontes (2000), Scudeller et al. (2001) e Scudeller (2002) demonstraram que a Floresta Ombrófila Densa é bastante heterogênea floristicamente e que há substituição de espécies ao longo de sua distribuição geográfica. Evidenciaram ainda que entre os trechos de Floresta Ombrófila Densa e Floresta Estacional Semidecidual do sudeste do Brasil há uma contínua distribuição de espécies arbóreas sem que possam ser estabelecidas espécies indicadoras para cada formação, sendo a altitude uma variável limitante para algumas espécies. No entanto, com enfoque na região sudeste, estes autores incluíram poucos trabalhos em FOM nas suas análises, e aparentemente, a substituição dos táxons na transição entre a FOD e FOM na Serra do Mar paranaense ocorre de forma mais abrupta. Isto poderia ser explicado pelas diferenças climáticas mais acentuadas entre as duas regiões que estas formações ocupam na região sul, o que inclui a presença mais forte de geadas no planalto.

Ademais, tanto a composição como a estrutura da área amostrada, além de sua peculiar localização e presença de espécies ameaçadas de extinção indicam que esta região merece rigorosa conservação.

\section{Agradecimentos}

Os autores agradecem a SANEPAR por disponibilizar a área de estudo, à Márcia H. Beltrame pela ajuda no campo e ao taxonomista Marcos Sobral pelas identificações em Myrtaceae. O primeiro autor recebe bolsa de mestrado e o segundo bolsaprodutividade, ambos do CNPq.

\section{Literatura citada}

APG (Angiosperm Phylogeny Group) II. 2003. An update of the Angiosperm Phylogeny Group classification for the orders and families of flowering plants: APG II. Botanical Journal of the Linnean Society 141: 399-436.

Baitello, J.P. 2003. Lauraceae. In: H.M. Longhi-Wagner, V. Bittrich, M.G.L. Wanderley \& G.J. Shepherd (eds.). Flora Fanerogâmica de São Paulo, v.3, São Paulo, pp. 149-223.

Blum, C.T. 2006. A Floresta Ombrófila Densa na Serra da Prata, Parque Nacional Saint-Hilaire/Lange, PR Caracterização Florística, Fitossociológica e Ambiental de um Gradiente Altitudinal. Dissertação de Mestrado, Universidade Federal do Paraná, Curitiba.

Fidalgo, O. \& Bononi, V.L.R. (coords.) 1989. Técnicas de coleta, preservação e herborização de material botânico. Série Documentos, Instituto de Botânica, São Paulo.

Fracker, S.B. \& Brischle, H.A. 1944. Measuring the local distributions of ribes. Ecology 25: 283-303.

França, G.S. \& Stehmann, J.R. 2004. Composição florística e estrutura do componente arbóreo de uma floresta altimontana no município de Camanducaia, Minas Gerais, Brasil. Revista Brasileira de Botânica 27: 19-30.

Galvão, F., Kuniyoshi, Y.S. \& Roderjan, C.V. 1989. Levantamento fitossociológico das principais associações arbóreas da Floresta Nacional de Irati, PR. Revista Floresta 19: 30-49.

Galvão, F., Roderjan, C.V., Kuniyoshi, Y.S. \& Ziller, S.R. 2002. Composição florística e fitossociologia de caxetais do litoral do estado do Paraná - Brasil. Revista Floresta 32: 17-39.

Gomes, E.P.C., Mantovani, W. \& Kawall, M. 2000. Estrutura e status sucessional de florestas na bacia do Rio Ribeira de Iguape, Vale do Ribeira, SP. Anais do V Simpósio de Ecossistemas Brasileiros, IESP 109: 170-183.

Gomes, E.P.C., Fisch, S.T.V. \& Mantovani, W. 2005. Estrutura e composição do componente arbóreo na Reserva Ecológica do Trabiju, Pindamonhangaba, SP, Brasil. Acta Botânica Brasilica 19: 451-464.

Hatschbach, G.G. \& Ziller, S.R. 2005. Lista vermelha de plantas ameaçadas de extinção no Estado de Paraná. SEMA/GTZ, Curitiba.

IAPAR. 1994. Cartas climáticas do estado do Paraná. Documento 18, Instituto Agronômico do Paraná, Londrina.

IBGE. 1992. Manual técnico da Vegetação Brasileira. Manuais Técnicos de Geociências $n^{0} 1$, Fundação Instituto Brasileiro de Geografia e Estatística, Rio de Janeiro. 
IPNI. 2006. The International Plant Names Index. http:// www.ipni.org (acesso em 10.07.2006).

ITCF. 1987. Plano de Gerenciamento da Área Especial de Interesse Turístico do Marumbi. Governo do estado do Paraná, Curitiba.

Klein, R.M. \& Hatschbach, G. 1962. Fitofisionomia e notas sobre a vegetação para acompanhar a planta fitogeográfica do Município de Curitiba e Arredores (Paraná). Boletim da Universidade Federal do Paraná, Geografia Física 4: 1-29.

Klein, R.M. 1962. Fitofisionomia e notas sobre a vegetação para acompanhar a planta fitogeográfica de parte dos Municípios de Rio Branco do Sul, Bocaiúva do Sul, Almirante Tamandaré e Colombo (Pr.). Boletim da Universidade do Paraná - Geografia Física 3: 1-33.

Klein, R.M. 1980. Ecologia da flora e vegetação do Vale do Itajaí. Sellowia 31-32: 1-389.

Klein, R.M. 1984. Aspectos dinâmicos da vegetação do sul do Brasil. Sellowia 36: 5-54.

Lacerda, A.E.B. 1999. Levantamento florístico e estrutural de vegetação secundária em área de contato da Floresta Ombrófila Densa e Mista, PR. Dissertação de Mestrado, Universidade Federal do Paraná, Curitiba.

Legrand, C.D. \& Klein, R.M. 1971. Myrtáceas, VI. Calyptranthes. In: R. Reitz (ed.). Flora Ilustrada Catarinense, Itajaí, pp. 489-552.

Leite, P.F. 2002. Contribuição ao conhecimento fitoecológico do sul do Brasil. Revista Ciência \& Ambiente 24: 51-73.

Maack, R. 1981. Geografía Física do estado do Paraná, $2^{\text {a }}$ ed. José Olympio, Rio de Janeiro.

Magurran, A.E. 1988. Ecological Diversity and Its Measurement. Princeton University Press, New Jersey.

Mantovani, W., Ruschel, A.R., Puchalski, A., Silva, J.Z., Reis, M.S. \& Nodari, R.O. 2005. Diversidade de espécies e estrutura sucessional de uma formação secundária da floresta ombrófila densa. Scientia Forestalis 67: 14-26.

Mcaleece, N. 1997. Biodiversity Pro Professional. Oban, Scotland.

Mueller-Dombois, D. \& Ellenberg, H. 1974. Aims and methods of vegetacion ecology. Wiley \& Sons, New York.

Nascimento, A.R.T., Longhi, S.J. \& Brena, D.A. 2001. Estrutura e padrões de distribuição espacial de espécies arbóreas em uma amostra de Floresta Ombrófila Mista em Nova Prata, RS. Ciência Florestal 11: 105-119.

Negrelle, R.R.B. \& Leuchtenberger, R 2001. Composição e estrutura do componente arbóreo de um remanescente de Floresta Ombrófila Mista. Revista Floresta 31: 42-51.

Negrelle, R.R.B. \& Silva, F.C. 1992. Fitossociologia de um trecho de Floresta com Araucária angustifólia (Bert.) O. Ktze. no município de Caçador-SC. Boletim de Pesquisa Florestal 24/25: 35-54.
Oliveira, Y.M.N. \& Rotta, E. 1982. Levantamento da estrutura horizontal de uma mata de araucária no primeiro planalto paranaense. Boletim de Pesquisa Florestal 4: 1-46.

Oliveira Filho, A.T. \& Fontes, M.A.L. 2000. Patterns of floristic differentiation among Atlantic Forest in SouthEastern in Brazil and the influence of climate. Biotropica 32: 793-810.

Rambo, B. 1953. História da flora do Planalto Riograndense. Sellowia 5: 184-232.

Roderjan, C.V. 1994. O gradiente da Floresta Ombrófila Densa no Morro do Anhangava, Quatro Barras, PR aspectos climáticos, pedológicos e fitossociológicos. Tese de Doutorado, Universidade Federal do Paraná, Curitiba.

Roderjan, C.V., Galvão, F., Kuniyoshi, Y.S., Hatschbach, G.G. 2002. As unidades fitogeográficas do estado do Paraná. Revista Ciência \& Ambiente 24: 75-92.

Rondon Neto, R.M., Kozera, C., Andrade, R.R., Cecy, A.T., Hummes, A.P., Fritzsons, E., Caldeira, M.V.W., Maciel, M.N.M. \& Souza, M.K.F. 2002. Caracterização florística e estrutural de um fragmento de Floresta Ombrófila Mista, em Curitiba, PR, Brasil. Revista Floresta 32: 3-16.

Schmitt, J.L. \& Windisch, P.G. 2005. Aspectos ecológicos de Alsophila setosa Kaulf. (Cyatheaceae, Pteridophyta) no Rio Grande do Sul, Brasil. Acta Botanica Brasilica 19: 859-865.

Schorn, L.A. 1992. Levantamento florístico e análise estrutural em três unidades edáficas em uma Floresta Ombrófila Densa Montana no estado do Paraná. Dissertação de Mestrado, Universidade Federal do Paraná, Curitiba.

Scudeller, V.V., Martins, F.R. \& Shepherd, G.J. 2001. Distribution and abundance of arboreal species in the atlantic ombrophilous dense forest in Southeastern Brazil. Plant Ecology 152: 185-199.

Scudeller, V.V. 2002. Análise fitogeográfica da Mata Atlântica - Brasil. Tese de Doutorado, Universidade Estadual de Campinas, Campinas.

Silva, F.C. \& Marconi, L.P. 1990. Fitossociologia de uma Floresta com Araucária em Colombo, PR. Boletim de Pesquisa Florestal 20: 23-38.

Silva, F.C. 1994. Composição florística e estrutura fitossociológica da floresta tropical ombrófila da encosta Atlântica no município de Morretes, estado do Paraná. Acta Biológica Paranaense 23: 1-54.

Smith, A.R., Pryer, K.M., Schuettpelz, E., Korall, P., Schneider, H. \& Wolf, P.G. 2006. A classification for extant ferns. Taxon 55: 705-731.

Tabarelli, M. \& Mantovani, W. 1999. Regeneração de uma floresta tropical montana após corte e queima (São Paulo - Brasil). Revista Brasileira de Biologia 59: 239-250. 